\title{
JURNAL GANTANG
}

e-ISSN: 2548-5547

p-ISSN: 2503-0671

http://ojs.umrah.ac.id/index.php/gantang/index

\section{Pengembangan Perangkat Pembelajaran Berbasis Model Pembelajaran Discovery Learning pada Materi Matematika Berorientasi Mitigasi Bencana}

\author{
Rima Tusa'diah' ${ }^{1}$, Yerizon $^{2 *}$ \\ ${ }^{1,2}$ Universitas Negeri Padang, Sumatera Barat, 25171, Indonesia \\ Pengiriman: 28/Oktober/2019; Diterima: 24/Maret/2020; Publikasi: 31/Maret/2020 \\ DOI: https://doi.org/10.31629/jg.v5i1.1898
}

\begin{abstract}
Abstrak
Sepanjang 2019 di Indonesia, Badan Nasional Penanggulangan Bencana (BNPB) mencatat telah terjadi 3721 bencana dan bencana alam yang paling sering terjadi adalah banjir bandang dan tanah longsor. Indonesia berada pada urutan ke-36 dengan indeks resiko 10,36 di bawah India dan Islandia. Oleh karena itu, pemerintah menganjurkan pendidikan tentang mitigasi bencana alam agar di berikan di sekolah. Tujuan dari penelitian ini adalah untuk melihat pengetahuan peserta didik tentang mitigasi bencana alam. Jenis penelitian ini adalah deskriptif kuantitatif. Instrumen penelitian adalah angket tentang mitigasi bencana alam yang telah divalidasi oleh salah satu dosen pendidikan matematika. Dari penelitian ini terbukti bahwa sekitar 88,9\% peserta didik MTsN 1 Padang menyatakan tidak adanya pembelajaran tentang pengenalan mitigasi bencana. Pengetahuan mitigasi bencana alam tidak harus diberikan dalam bentuk pembelajaran khusus, namun dapat di integrasikan dalam mata pelajaran yang sudah ada, seperti matematika.
\end{abstract}

Kata kunci: mitigasi bencana; model discovery learning

\begin{abstract}
During 2019 in Indonesia, BNPB recorded 3721 disasters, and the most common natural disasters were flash floods and landslides. Indonesia is ranked 36th with a risk index of 10.36 below India and Iceland. Therefore, the Government recommends education on disaster mitigation to be provided in schools. This study aims to examine the improvement of students' understanding of disaster mitigation. This research is a quantitative descriptive. The instrument of research is questionnaire about disaster mitigation which was validated by expert of mathematics education. The results show that around $88.9 \%$ of students at MTsN 1 Padang stated that there is no learning about the introduction of disaster mitigation. Knowledge of disaster mitigation does not have to be given in the form of special learningbut can be integrated in existing subjects, such as mathematics.
\end{abstract}

Keywords: disaster mitigation, discovery learning

\section{Pendahuluan}

Indonesia termasuk salah satu negara yang berpotensi besar terjadinya bencana alam. Hal tersebut dibuktikan dengan penelitian oleh Universitas Ruhr Bochum, Jerman, dan Koalisi
LSM kemanusiaan Jerman, Development Helps Alliance, bahwa Indonesia berada pada urutan ke-36 dengan indeks resiko 10,36 dibawah India dan Islandia (Heinttze dkk, 2018). Berbagai bencana alam terjadi di Indonesia dan terus

*Penulis Korespondensi

Email Address: yerizon@fmipa.unp.ac.id

Handphone : +6281363455577 
JURNAL GANTANG. Maret 2020; V(1): 69 - 76

p-ISSN. 2503-0671

e-ISSN. 2548-5547

mengalami peningkatan setiap tahunya. Sepanjang 2019 Badan Nasional Penanggulangan Bencana (BNPB) mencatat terjadi 3721 bencana, diantaranya banjir bandang, tanah longsor, kebakaran hutan dan masih banyak lagi peristiwa alam lainya. Bencana alam tersebut mengakibatkan Korban meninggal 475 dan hilang 108 orang (Tempo.co, Jakarta- BNPB, 17 desember 2019). Bencana alam bisa terjadi secara tiba-tiba dan mengakibatkan kerugian materil maupun material, dan pada saat bencana ini terjadi banyak masyarakat yang tidak siap dan tidak tau bagaimana cara penanggulangan bencana yang telah terjadi, karena masih banyaknya masyarakat yang belum memiliki pengetahuan bagaimana penanggulan bencana alam.

Untuk mengatasi ini semua maka pengetahuan tentang mitigasi bencana alam perlu diberikan kepada masyarakat sejak dini. Anakanak akan lebih mudah mengalami trauma jika menjadi korban bencana alam, oleh karena itu, pemahaman serta pengetahuan kepada anak agar tidak panik serta trauma saat bencana perlu diberikan (Nugroho dkk, 2012). Pembelajaran mitigasi bencana alam lebih baik diberikan melalui pembelajaran formal, khususnya di jenjang Sekolah Menengah Pertama (SMP). Anak pada jenjang SMP berada pada usia perkembangan aspek kognitif, psikomotor dan efektif yang sangat pesat (Nurbaedah, 2013).

Pengetahuan mitigasi bencana tidak harus diberikan dalam bentuk pembelajaran khusus. Namun dapat di integrasikan dalam mata pelajaran yang sudah ada, seperti matematika (Hasanah dkk, 2016). Ini sesuai dengan pernyataan Presiden Jokowi dalam sidang kabinet paripurna di Istana Negara, Jakarta, Senin (7/1/2019). "Sebagai negara di tempat rawan bencana alam, ring of fire, kita harus siap merespons dan tanggung jawab menghadapi segala bencana alam. Saya minta edukasi lebih baik, konsisten dan lebih dini bisa masuk ke dalam muatan sistem pendidikan kita," ujar Presiden Jokowi yang dikutip dari (Kompas.com).
Beberapa penelitian yang mencoba memasukan mitigasi bencana ke dalam pembelajaran. Nugroho (2012) menyatakan bahwa pengetahuan peserta didik di usia dini tentang mitigasi bencana alam masih perlu ditingkatkan lagi, oleh sebab itu dia mencoba mengembangkan media pembelajaran LUDO 3D-MB media ini dikembangkan dengan menerapkan materi bangun ruang sisi datar. LUDO 3D- MB merupakan media pembelajaran seperti permainan LUDO. Nama 3D-MB merupakan singkatan dari 3 Dimensi- Mitigasi Bencana sebab media ini digunakan untuk pembelajaran mitigasi bencana. LUDO 3D- MB terdiri dari tiga bagian, yakni bidang permainan, dadu, dan kartu Soal.

Media ini terdapat 24 kartu soal yang berisikan sebuah soal cerita yang di integrasikanya upaya mitigasi bencana alam. Dari penelitian yang dilakukan oleh Suwaibah, dkk menyatakan dengan media LUDO 3D- MB ini berhasil meningkatkan kemampuan peserta didik SMP Y Surabaya kelas VIII-A terhadap mitigasi bencana alam sebesar $2,11 \%$, Karena media pembelajaran LUDO ini mampu meningkatkan pengethuan peserta didik terhadap mitigasi bencana alam .

Untuk materi yang lain belum ada bahan ajar matematika yang memasukkan mitigasi bencana dalam pembelajaran. Untuk itu perlu dibuat bahan ajar atau perangkat yang lebih efektif lagi untuk meningkatkan pengetahuan peserta didik terhadap mitigasi bencana alam. Salah satu alternatif yang ditawarkan peneliti untuk menunjang penerapan mitigasi bencana pada mata pelajaran matematika adalah mengembangan perangkat yang berbasis model discovery learning yang berorentasi mitigasi bencana. Dalam penerapannya ini sangat bisa membantu peserta didik dalam mengenalkan mitigasi bencana alam.

Metode pembelajaran pada model discovery learning ini menekankan pentingnya dalam mengkonstruk ide-ide dalam suatu disiplin ilmu, melalui partisipasi aktif dari peserta didik dalam proses pembelajaran dan model 
pengajaran yang dikemangkan berdasarkan pandangan kognitif tentang pembelajaran dan prinsip-prinsip kontruktivitas atau biasa disebut juga dengan peserta didik membangun konsep sendiri (Hosnan, 2014: 281). Sedangkan menurut Bruner, penemuan terbimbing adalah metode pengajaran yang berbasis inquiri, sebuah teori pembelajaran konstruktif yang terdapat pada situasi problem solving dimana peserta didik menggunakan pengalaman dan pengetahuan mereka untuk menemukan fakta, hubungan, dan kebenaran-kebenaran baru untuk dipelajari, jadi dari pernyataan diatas dapat disimpulkan bahwa model discovery learning sengaja di rancang untuk menemukan sendiri informasi yang diperlukan agar peserta didik menemukan konsep dengan mandiri melalui bimbingan guru dalam bentuk pertanyaan (Winataputra, 2007).

Sama halnya Yang, Liao, Ching, Chang, dan Chan (2010) juga menyatakan bahwa metode discovery adalah salah satu metode yang mengurangi peran guru dan membuat peserta didik membangun pengetahuannya sendiri. Metode discovery mendorong peserta didik untuk aktif dalam proses pembelajaran dan dapat mengembangkan kemandirian belajar (Khan, 2014). Adapun dalam metode penemuan terbimbing ini, peserta didik menerima masalah untuk dipecahkan dengan guru memberikan petunjuk bagaimana memecahkan permaslahan tersebut agar peserta didik tetap pada arah yang benar (Mayer, 2002). Langkah-langkah metode penemuan terbimbing menurut Achera, Belecina, \& Garvida (2015) yaitu motivation, exploration, presentation, warp up, practice dan evaluation.

Dari pemaparan di atas maka selalaku peneliti merasa model berbasis discovery learning ini dapat membantu mengenalkan mitigasi bencana kepada peserta didik dan juga mampu menambah wawasan bagi peserta didik bagaimana melindungi diri dari bencana alam. Dalam pengembangan perangkat ini ada beberapa materi matematika yang biasa digunakan, contohnya saja pada materi lingkaran dan bangun ruang sisi datar. Materi ini dipilih karena dapat diaplikasikan dalam pembelajaran mitigasi bencana alam seperti banjir dan tanah longsor melalui soal cerita.

Materi lingkaran dan bangun ruang sisi datar menjadi materi yang penting karena keberadaanya mudah dijumpai dalam kehidupan sehari hari. Cakupan materi ini meliputi balok, kubus, prisma dan limas (Lestari, Rohaeti, \& Purwasih, 2018). Meski lingkaran dan bangun ruang sisi datar kerap dijumpai dalam kehidupan sehari- hari kenyataannya masih banyak peserta didik belum mampu mengaplikasikan materi ini dalam kehidupan sehari- hari, salah satu faktor penyebabnya adalah pemahaman peserta didik masih terbatas (Rahayu \& KHolillah, 2018). Adanya perangkat pembelajaran berbasis model discovery learning diharapkan mampu memberikan wawasan kepada peserta didik mengenai kegunaan materi bangun ruang sisi dapat meningkatkan kemampuan matematis peserta didik, selain sebagai upaya pengenalan mitigasi bencana.

\section{Metode Penelitian}

Jenis penelitianya adalah pengembangan perangkat pembelajaran berbasis model discovery learning. Metode penelitian yang digunakan adalah metode deskriptif kuantitatif (Arikunto, 2010). Penelitian ini dilaksanakan di salah satu MTsN 1 Padang kelas VIII-4. Pengumpulan data dilakukan dengan metode dokumentasi dan observasi. Instrumen penelitian berupa angket mitigasi bencana alam yang telah divalidasi oleh salah satu dosen pendidikan matematika (Hera Deswita). Analisis atau pengolahan data menggunakan teknik deskriptif untuk menggambarkan tingkat pengetahuan peserta didik tentang mitigasi bencana alam, yang dipusatkan pada pengembangan perangkat pembelajaran matematika yang berbasis model discovery learning berorientasi mitigasi bencana alam. Penyajian data merupakan sekumpulan informasi yang tersusun dan memberi kemungkinan adanya penarikan kesimpulan dan pengambilan tindakan. Penarikan kesimpulan disusun berdasarkan pola-pola induktif selama penelitian berlangsung dan data yang perlu diuji 
JURNAL GANTANG. Maret 2020; V(1): 69 - 76

p-ISSN. 2503-0671

e-ISSN. 2548-5547

kebenarannya, kekokohannya, dan kecocokannya. Melalui penelitian ini yang akan dilihat adalah pengetahuan peserta didik tentang mitigasi bencana alam, yang diperoleh sdari angket yang diedarkan peneliti. Serta upaya pengembangan perangkat pembelajaran berbasis model discovery learning yang berorientasi mitigasi bencana alam.

\section{Hasil dan Pembahasan}

Pada bagian ini dipaparkan mengenai pengetahuan pesera didik tentang mitigasi bencana alam serta implementasi pengembangan perangkat pembelajaran berbasis model discovery learning yang berorientasi mitigasi bencana alam. Perangkat pembelajaran berbasis model discovery learning merupakan alat untuk membantu peserta didik mengenal pentingnya pengetahuan tentang bencana alam, perangkat dirancang khusus untuk peserta didik di jenjang SMP, karena masih banyak sekali peserta didik yang tidak peduli pentingnya memiliki pengetahuan tentang mitigasi bencana, ini terbukti setelah melakukan observasi di MTsN 1 Padang dan dari data yang di dapat terlihat, masih sangat banyak anak SMP yang belum memahami pengetahuan mitigasi bencana dengan baik. Dari hasil angket pemahaman mitigasi bencana yang di sebarkan di MTsN 1 Padang Kelas VIII- 4.

Pada angket yang di edarkan membahas tentang pengetahuan sekitar mitigasi bencana, ada beberapa poin dari angket yang sangat penting diketahui peserta didik contohnya Membuang sampah tidak pada tempatnya seperti membuang sampah ke sungai ini adalah salah satu faktor penyebab terjadinya banjir. Aktivitas dan tindakan manusia seperti pertambahan jumlah penduduk, moral hazard manusia seperti membuang sampah di sungai, merubah berbagai tipe lahan untuk berbagai kepentingan (BP DAS Wampu Sei Ular, 2013). Dari point ini hanya sekitar $70 \%$ peserta didik yang menyatakan pernyataan itu benar sekitar $30 \%$ peserta didik tidak mengetahui bahwa membuang sampah sembarangan adalah salah satu faktor penyebab terjadinya banjir.

Poin selanjutnya yaitu lingkungan hutan harus dilindungi dari penebangan liar ini adalah salah satu cara pencegahan terjainya longsor. Sesuai dengan hasil analisis GFW juga mengindikasikan kegiatan perambahan hutan dan penambangan liar yang marak telah menyebabkan kerusakan DAS di hulu sungai, yang memperbesar risiko terjadinya banjir dan longsor. Untuk poin ini sekitar 38\% yang menyatan iya dan sekitar $68 \%$ peserta didik menyatan bahwa penebangan liar tidak merupakan salah satu penyebab terjadinya bencana tanah longsor. Poin berikutnya pencegahan yaitu penanaman pohon (reboisasi) merupakan salah satu cara pencegahan banjir dan tanh longsor pada pernyataan ini hanya sekitar $48 \%$ yang menyatakan iya sekitar $52 \%$ peserta didik menyatan tidak.

Sangat disayangkan sekali karena masih banyak peserta didik yang tidak mengetahi apa penyebab dan bagaimana cara pencegahan bencana banjir dan tanah longsor padahal menurut analisis Aqueduct Global Flood Analyzer, Indonesia adalah negara dengan jumlah populasi terdampak bencana banjir terbesar ke-6 di dunia. Berdasarkan data Badan Nasional Penanggulangan Bencana (BNPB) banjir yang disertai longsor menjadi bencana ke6 yang paling sering terjadi di Indonesia dengan 32 kejadian setiap tahunnya.Inilah presentase keseluruhan dari isi angket yang diberikan peserta didik untuk mengetahui seberapa pengetahuan peserta didik tentang mitigasi bencana alam dapat dilihat pada tabel 1 .

Tabel 1.

Presentase pengetahuan dan sikap peserta didik tentang mitigasi bencana.

\begin{tabular}{lcccc}
\hline & \multicolumn{3}{c}{ Persentase Peserta Didik } \\
\cline { 2 - 5 } $\begin{array}{l}\text { Mitigasi } \\
\text { Bencana }\end{array}$ & \multicolumn{2}{c}{ Pengetahuan } & \multicolumn{2}{c}{ Sikap } \\
\cline { 2 - 5 } & Paham & Tidak & Peduli & $\begin{array}{c}\text { Tidak } \\
\text { Peduli }\end{array}$ \\
\hline Banjir & 45 & 54 & 40 & 60 \\
\hline $\begin{array}{l}\text { Tanah } \\
\text { Longsor }\end{array}$ & 45 & 54 & 40 & 60 \\
\hline
\end{tabular}

Persentase diatas menjelaskan bahwa masih banyak peserta didik yang tidak memiliki 
pemahaman tentang mitigasi bencana alam, ini terbukti dari presentase pada tabel tersebut menyatakan sekitar $60 \%$ peserta didik memiliki sikap tidak peduli terhadap bencana alam ini disebabkan tidak adanya pembelajaran yang mengkaitkanmaterinya dengan mitigasi bencana alam dan disamping itu juga tidak adanya sosialisasi yang diberikan kepada peserta didik tentang bagaimana mitigasi bencana alam pernyataan ini dapat dibuktikan dari survei yang telah dilakukan bahwa sekitar, $88.9 \%$ peserta didik menyatakan tidak mendapatkan sosialisasi maupun pembelajaran tentang tanggap bencana alam. Itulah yang menyebabkan banyak peserta didik yang memiliki sikap acuh tak acuh saja tentang pentingnya pengetahuan mitigasi bencana alam.

Dari pemaparan di atas maka dapat disimpulkan bahwa pengetahuan peserta didik tentang tanggap bencana masih terbilang dan beberapa dari peserta didik juga tidak menghiraukanya dikarenakan tidak ada keterkaitannya dengan pembelajaran disekolah, ini sangat disayangkan sekali karena sekolah MTsN 1 Padang ini merupakan salah satu sekolah yang rawan banjir jika terjadi hujan deras yang tidak kunjung berhenti. Seharusnya peserta didik MTsN 1 Padang lebih peduli lagi terhadap tanggap bencana, tapi pada kenyataanya mereka tidak memperdulikanya, oleh sebab itu peneliti tertarik untuk melakukan penelitianya di MTsN 1 Padang guna peserta didik MTsN 1 Padang biasa lebih sadar dan peduli tentang pentingnya pengetahuan tanggap bencana. Oleh karena itu, diperlukan pembelajaran mengenai mitigasi bencana disekolah mengingat interaksi anak lebih banyak disekolah dan banyak pengetahuan yang di dapat di sekolah. dari pernyataan- pernyataan diatas maka selaku peneliti ingin mengembangkat perangkat pembelajaran berbasis model discovery learning berorientasi mitigasi bencana alam guna agar peserta didik mengetahui sangat penting pengetahuan tentang mitigasi bencana alam dan peserta didik menjadi lebih peduli mengenai mitigasi bencana alam.
Perangkat pembelajaran yang berbasis model discovery learning berorentasi mitigasi bencana ini di rancang khusus guna untuk mengenalkan pentingnya pengetahuan mitigasi bencana alam. Implementasinya pada satuan pendidikan SMP/ MTsN. Pada perangkat berbasi model discovery learning ini memiliki beberapa tahapan dapat dilihat pada tabel 2 dibawah ini.

Tabel 2.

Tahap- tahap pembelajaran model discovery learning.

\begin{tabular}{|c|c|}
\hline Tahap-tahap & Kegiatan Guru \\
\hline $\begin{array}{l}\text { Tahap } 1 \\
\text { Stimulation (pemberian } \\
\text { rangsangan) }\end{array}$ & $\begin{array}{l}\text { Menyampaikan tujuan } \\
\text { pembelajaran dan memotivasi } \\
\text { peserta didik dengan mendorong } \\
\text { peserta didik terlibat dalam } \\
\text { kegiatan. Serta memberikan } \\
\text { masalah yang berkaitan dengan } \\
\text { materi pembelajaran yang } \\
\text { diorientasikan kepada mitigasi } \\
\text { bencana alam }\end{array}$ \\
\hline $\begin{array}{l}\text { Tahap } 2 \\
\text { Problem statement } \\
\text { (pernyataan identifikasi } \\
\text { masalah) }\end{array}$ & $\begin{array}{l}\text { Membimbing peserta didik } \\
\text { dalam merumuskan hipotesis } \\
\text { sesuai dengan masalah yang ada }\end{array}$ \\
\hline $\begin{array}{l}\text { Tahap } 3 \\
\text { Data collection } \\
\text { (pengumpulan data) }\end{array}$ & $\begin{array}{l}\text { Membimbing peserta didik } \\
\text { melakukan kegiatan penemuan } \\
\text { dengan mengarahkan peserta } \\
\text { didik untuk memperoleh } \\
\text { informasi yang diperlukan } \\
\end{array}$ \\
\hline $\begin{array}{l}\text { Tahap } 4 \\
\text { Data processing } \\
\text { (pengolahan data) }\end{array}$ & $\begin{array}{l}\text { Membimbing peserta didik } \\
\text { memilih dan menggunakan } \\
\text { prosedur yang tepat untuk } \\
\text { memperoleh solusi dari } \\
\text { permasalahan }\end{array}$ \\
\hline $\begin{array}{l}\text { Tahap } 5 \\
\text { Verification } \\
\text { (pembuktian) }\end{array}$ & $\begin{array}{l}\text { Membimbing peserta didik } \\
\text { dalam memeriksa kembali dan } \\
\text { membuktikan benar atau } \\
\text { tidaknya hipotesis dengan } \\
\text { temuannya }\end{array}$ \\
\hline $\begin{array}{l}\text { Tahap } 6 \\
\text { Generalization } \\
\text { (menarik kesimpulan }\end{array}$ & $\begin{array}{l}\text { Membimbing peserta didikan } \\
\text { dalam menyajikan hasil } \\
\text { kegiatan, merumuskan } \\
\text { kesimpulan/menemukan konsep }\end{array}$ \\
\hline
\end{tabular}

Sumber: materi pelatihan guru implementasi kurikulum 2013

Pengetahuan dan pemahaman yang diperoleh dari pembelajaran penemuan terbimbing akan lebih tahan lama, melatih kemampuan penalaran dan melatih kemampuan berpikir bebas. Hal ini sesuai dengan pendapat Dahar (2011: 80) yang menyatakan bahwa beberapa keuntungan belajar penemuan 
JURNAL GANTANG. Maret 2020; V(1): 69 - 76

p-ISSN. 2503-0671

e-ISSN. 2548-5547

terbimbing yaitu: (1) pengetahuan bertahan lama dan mudah diingat; (2) hasil belajar penemuan terbimbing mempunyai efek transfer yang lebih baik dari pada hasil lainnya; (3) secara menyeluruh belajar penemuan terbimbing meningkatkan penalaran peserta didik dan kemampuan untuk berpikir bebas. Selain keunggulan di atas, pembelajaran penemuan terbimbing juga unggul dalam mengaktifkan peserta didik, melibatkan peserta didik dalam pembelajaran, memberi rasa puas pada peserta didik, dan melatih peserta didik belajar lebih mandiri. Hal ini sesuai dengan pendapat Suherman, dkk (2003: 214).

Penjelasan di atas tentang model discovery learning peneliti berpikir dengan dikembangkan perangkat pembelajaran berbasis model discovery learning akan mampu membantu untuk mengenalkan mitigasi bencana alam kepada peserta didik. Karena proses pembelajaran model discovery learning ini sangat terstruktur dan berpusat kepada peserta didik dimana pada proses pembelajaran peserta didik yang paling dominan guru hanya sebagai fasilitator. Pembelajaran yang berbasis model discovery learning ini akan sangat menarik bagi peserta didik karna peserta didik akan merasa sangat tertantang dengan permasalahanpermsalahan yang ada. Di bawah ini merupakan contoh implementasi mitigasi bencana alam pada materi matematika.

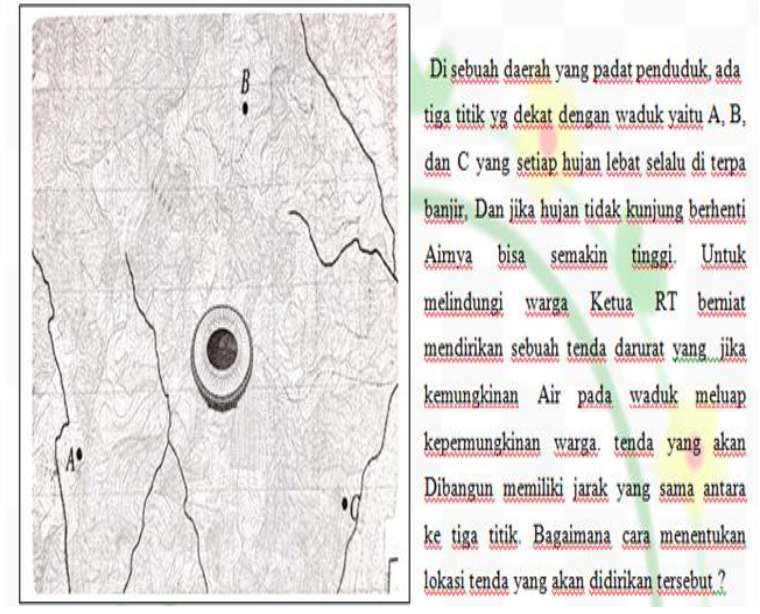

Gambar 1. Implementasi mitigasi bencana pada materi lingkaran

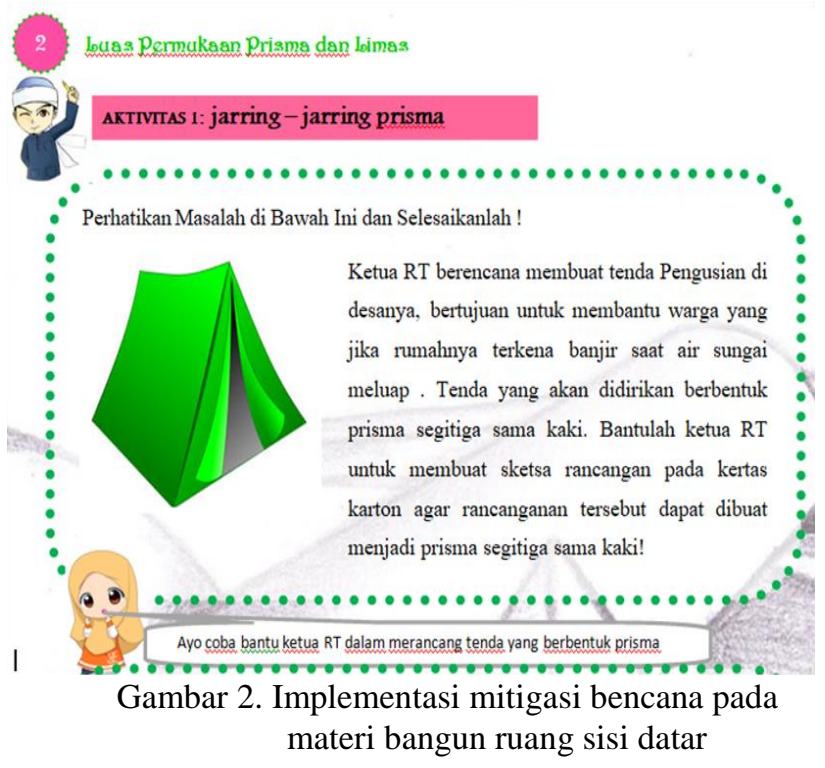

Salah satu contoh penerapan pengetahuan mitigasi bencana alam pada materi lingkaran, pada materi ini peserta didik dibimbing dalam menentuka unsur- unsur lingkaran, untuk menentukan unsur- unsur lingkaran ini peserta didik di berikan sebuah soal kontekstual yang di integrasikan kepada salah satu upaya penyelamatan diri pada bencana alam banjir, seperti "Disebuah desa yang pada penduduk ada tiga titik yang dekat dengan waduk yaitu A, B, dan C yang setiap terjadinya hujan deras yang selalu diterpa banjir, dan jika hujuan tidak kunjung berhenti arinya bisa semakin tinggi. Untuk melindungi warga Ketua RT berniat mendirikan sebuah tenda darurat yang jika kemungkinan air pada waduk meluap kepermungkiman warga. Tenda yang akan dibangun memiliki jarak yang sama antara ketiga titik. Bagaimana cara menentukan lokasi yang akan didirikan tersebut?"

Pada penyelesaian masalah kontekstual tersebut peserta didik harus menentukan sebuah titik yang berjarak sama terhadap titik A, B, dan C. Untuk memenuhi hal itu titik tersebut harus merupakan titik pusat lingkaran, diamana titik A, $\mathrm{B}$, dan $\mathrm{C}$ berada pada keliling atau busur lingkaaran. Kegiatan- kegiatan yang akan dikerjakan oleh peserta didik berupa 1. Membuat sumbu ruas garis $A B$, yaitu garis yang tegak lurus $\mathrm{AB}$ dan melalui titik tengah $\mathrm{AB}, 2$. 
Membuat sumbu ruas garis $\mathrm{BC}$, yaitu garis yang tegak lurus $\mathrm{BC}$ dan memiliki titik tengah $\mathrm{BC}, 3$. Titik potong sumbu ruas garis $\mathrm{AB}$ dan sumbu ruas garis $\mathrm{BC}$ merupakan titik pusat lingkaran yang diberinama $\mathrm{O}$, dimana lingkarannya melalui titik A, B, dan C.

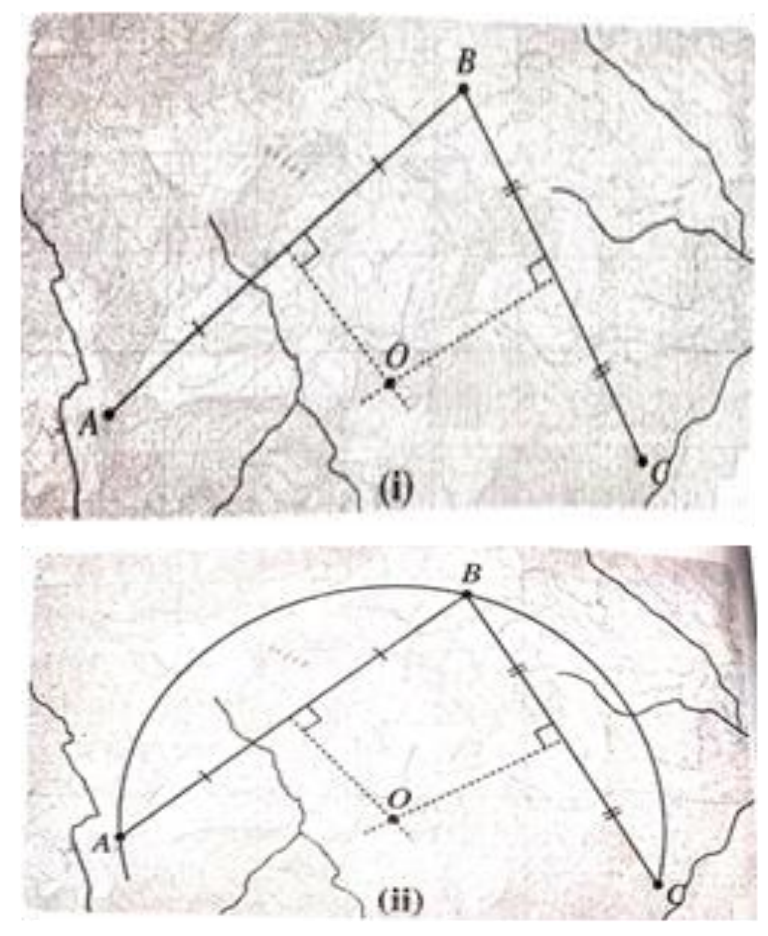

Gambar 2. Contoh jawaban

Pada gambar menunjukan langkahlangkah pengerjaan lukisan dan pada gambar (ii) terlihat busur lingkaran melalui titik A, B, maupun $\mathrm{C}$, dengan demikian, titik $\mathrm{O}$ merupakan lokasi stadion yang akan dibangun.

\section{Kesimpulan}

Berdasarkan permasalahan mengenai kurangnya pemahaman mitigasi bencana alam bagi masyarakat di Indonesia khususnya bagi anak- anak, maka dibuat perangkat pembelajaran berbasis model discovery learningberorientasi mitigasi bencana alam sebagai solusi alternatif untuk pengenalan mitigasi bencana pada pembelajaran matematika. Perangkat pembelajaran berbasis model discovery learning yang diranncang khusus agar dapat digunakan untuk peserta didik tingkat SMP/ MTsN.

\section{Referensi}

Achera, L. J., Belecina, R. R., \& Garvida, M. D.
(2015). The effect of group guided discovery approach on the performance of students in geometry. International Journal of Multidisciplinary Research and Modern Education (IJMRME), 1(2), 331342

Arikunto, S. (2010). Prosedur penelitian suatu pendekatan praktik. Jakarta: Rineka Cipta.

Badan Geologi. (2015). Mengenal sesar aktif. majalah GEOMAGZ. Tersedia di: geomagz.geologi.esdm.go.id/me ngenalsesar-aktif/ (Diakses: 24 Februari 2019).

[BPDAS] Balai Pengelolaan Daerah Aliran Sungai Wampu-Sei Ular. (2013). Base Line DAS Padang. Balai Pengelolaan Daerah Aliran Sungai Wampu Sei Ular. Medan.

Dahar, Ratna Wilis. (2011). teori-teori belajar dan pembelajaran. Jakarta: Erlangga

Suwaibah, D., Anggraini, L., \& Mursyidah, H. (2019). LUDO 3D-MB media sebagai pengenalan mitigasi bencana alam berbasis pembelajaran matematika materi bangun ruang. Jurnal Ilmiah Pendidikan Matematika, 4(1), 12-19.

Hasanah, I. Sri Wahyuni, S. Bachtiar, R W. (2016). Pengembangan modul mitigasi bencana berbasis potensi lokal yang terintegrasi dalam pelajaran IPA di SMP. Jurnal Pembelajaran Fisika, 5(3), 226 234

Haswati, D. \& Nopitasari, D. (2019) Implementasi bahan ajar persamaan diferensial dengan metode guided discovery berbantu software mathematica untuk meningkatkan pemahaman konsep. Jurnal Gantang, 4(2), 97-102.

Heintze, H. J. dkk. (2018). World risk report 2018. Jermany: Bundnis Entwicklung Hilft.

Deswita, H. (2017). Profil tingkat penguasaan keterampilan dasar mengajar mahasiswa pendidikan matematika universitas pasir pengaraian. Jurnal Gantang, 2(1), 51 -62.

Hosnan. (2014). Pendekatan saintifik dan kontekstual dalam pembelajaran matematika. Bogor: Ghalia Indonesia.

http:// Kompas. Com diakses tanggal 7 januari (2019).

Khan, Z. R. (2014). Using innovative tools to teach computer application to business students - A Hawthorne effect or successful implementation here to stay. 
JURNAL GANTANG. Maret 2020; V(1): 69 - 76

p-ISSN. 2503-0671

e-ISSN. 2548-5547

Journal of University Teaching \& Learning Practice, 11(1), 1-10.

Lestari, R. S., Rohaeti, E. E., \& Purwasih, R. (2018). Profil kemampuan koneksi matematis siswa smp dalam menyelesaikan soal bangun ruang sisi datar ditinjau dari kemampuan dasar. Jurnal Ilmiah.

Mayer, R. E. (2002). The promise of educational psychology, Vol II Teaching for Meaningful Learning. New Jersey: Pearson Education.

Nugroho, D. U., dkk. (2012). Sekolah petra (penanganan trauma) bagi anak korban bencana alam. Jurnal Ilmiah Mahasiswa, 2(2), 97-101.

Nurbaedah, N. S. (2013). Internalisasi nilai-nilai berpikir kritis melalui model pembelajaran inkuiri sains. Bandung: Universitas Pendidikan Indonesia.

Rahayu, P., \& Kholilullah. (2018). Validitas dan praktikalitas lembar kerja siswa berbasis pendekatan kontekstual materi bangun ruang sisi datar pada siswa SMP. Jurnal Ilmiah Pendidikan Matematika, 3(2), 126133.

Suherman, Erman dkk. (2003). strategi pembelajaran matematika kontemporer. Bandung: UPI.

Tempo.co, Jakarta- BNPB, 17 desember 2019.

Winataputra, U. S. (2007). Teori belajar dan pembelajaran. Jakarta: Universitas Terbuka.

Yang, E. F. Y., Liao, C. C. Y., Ching, E., Chang, T., \& Chan, T.-W. (2010). The effectiveness of inductive discovery learning in $1: 1$ mathematics classroom. In Proceedings of the 18th international conference on computers in education (ICCE) (pp. 743-747). Putrajaya, Malaysia: Asia-Pasific Society for Computers in Education. 